\title{
Ensino de História e Imagens: possibilidades de pesquisa
}

\author{
Ana Heloisa Molina
}

Doutora em História pela Universidade Federal do Paraná (UFPR). Professora do Departamento de História da Universidade Estadual de Londrina e do Programa de Pós-graduação em História Social da Universidade Estadual de Londrina. Autora de, entre outros artigos, "Alegorias sobre o moderno: os quadros 'Solidariedade Humana' e 'O progresso' de Eliseu Visconti (1866-1944)". Estudos Iberoamericanos. Porto Alegre. V. XXXI, 2005. anaheloisamolina@yahoo.com.br

\section{RESUMO}

Este texto propõe analisar alguns referenciais teóricos a respeito do conceito imagem, os meios e utilizações mais freqüentes em sala de aula pelos professores de história e principalmente o olhar de alunos do ensino fundamental e médio da rede pública quanto às especificidades das linguagens visuais e sua análise quanto ao uso em sala pelos seus professores.Desta forma, apontar os limites e os usos de imagens pelos professores de história e levantar, a partir das respostas dos alunos, as possibilidades de investigação da construção do conhecimento histórico.

PALAVRAS-CHAVES: ensino de história; imagens; construção do conhecimento.

\section{Abstract}

This text proposes the analysis of some theoretical references in respect to the concept of image, the means and the more frequent use of it, in the context of school classroom, by history teachers and principally the point of view of students from schools and high schools of Brazil's public school system about the visual languages specificities and their analysis about the use of them by their teachers. Therefore, the article points the limit and the use of image by history teachers and tries to identify, from students answers, possibilities to investigate the construction of historic knowledge.

KEY WORDS: history teaching; images; construction of the knowledge. 


\title{
Ensino de História e Imagens: possibilidades de pesquisa
}

\begin{abstract}
“Os antigos retratos de parede Não conseguem ficar por longo tempo abstratos Às vezes os seus olhos te fitam, obstinados Porque eles nunca se desumanizam de todo. Jamais te voltes para trás de repente Poderias pegá-los em flagrante."
\end{abstract}

Magias.

Rua dos cataventos e outros poemas.

Mário Quintana

Algumas interrogações sobre a pluralidade de imagens que nos são dadas a ver na iconosfera atual são necessárias e respeitando as diferenças e as especificidades entre a palavra e a imagem, devemos considerar as interfaces e o diálogo no intervalo destes dois espaços culturais.

No trajeto que vai das imagens indiciais (chamemo-las "imagens pictográficas": das artes tradicionais, da fotografia e do cinema), às imagens imateriais (procedentes em sua maioria da lógica computacional), emergiu um panorama visual marcado pela complexidade narrativa, por uma estética centrada nos procedimentos e mesmo pelo excesso de uso e exposição. É a imagemvelocidade, guiada pela diretriz computacional, que marca hoje, consideravelmente, o atual panorama imagético.

Modificou-se também a propriedade das imagens: elas já não são o exclusivo dos artistas, mas, desempenham funções sociais.
A imagem expandiu, e, neste processo, adquiriu, em grande medida, o status de virtualidade.

Neste universo em franca expansão como pensar a questão da visualidade como fenômeno social e como fonte de conhecimento histórico?

Poderíamos iniciar tal discussão a partir do mecanismo de criação e reprodução da imagem, no progresso paralelo do conhecimento dos processos analíticos que permitem decompor a imagem. $\mathrm{Na}$ perspectiva do figurativo ao virtual, o simultâneo e a manipulação da matriz imagética proporcionam novas fronteiras de análise e recombinações.

Os pesquisadores sobre o equipamento visual humano e os equipamentos mecânicos de produção de imagens do início do século XX não poderiam imaginar que poderíamos decompor e transformar o menor elemento constituinte da imagem, graças a outro aparelho, o computador. Desta forma, o pixel, 
para Couchot, transforma-se em ponto de convergência de duas linhas de investigação tecnológica: uma que procurava o máximo de automatismo na geração da imagem, outra, o domínio completo de seu constituinte mínimo.

A imagem é, daí por diante, reduzida a um mosaico de pontos perfeitamente ordenado, um quadro de números, uma matriz. Cada pixel é um permutador minúsculo entre imagem e número, que permite passar da imagem ao número e vice versa².

Esta questão está proposta também por Annateresa Fabris ${ }^{3}$ quando questiona o status da imagem e analisa o modelo, produto de abstrações formais, que toma cada vez mais o lugar da imagem especular, marcando a passagem da natureza para a linguagem e redefinindo o regime da visualidade contemporânea.

A imagem deixa de ser o antigo objeto óptico do olhar para converter-se em imagerie (produção de imagens), práxis operacional que insere o sujeito numa "situação experimental visual inédita", acrescida pela possibilidade de integrar outros registros da sensibilidade corporal, sobretudo o tato. ${ }^{4}$

Entre o figurativo e o virtual existem intercâmbios e zonas fronteiriças de aproximação, como a hibridação. "Hibridação enfim entre o pensamento tecno-científico, formalizável, automatizável e o pensamento figurativo criador, cujo imaginário nutre-se num universo simbólico da natureza diversa, que os modelos nunca poderão anexar"5.
Como o sujeito enquanto espectador e usuário de imagens criadas em computador, "experimentador" de videogames, em filmes, ficção, traillers publicitários, jogos, vinhetas entre tantos e outros se insere no mundo material e em um espaço e tempo simulado?

Sobre tal questão, Philippe Quéau propõe que "A passagem iminente das tecnologias de telecomunicações e do áudio-visual ao todo-numérico anuncia-se como a ocasião de uma reconfiguração dos saberes e dos métodos, das escritas e das memórias, dos meios de criação e de gestão"6

Ainda avança em suas reflexões

O fascínio pelos mundos virtuais e pelas imagens de síntese toca particularmente as jovens gerações. Este fascínio provém do fato de que não somente podemos criar pequenos "mundos" do nada, mas sobretudo pelo fato de que, num certo sentido, podemos habitar "realmente" esses mundos." "O virtual nos estimula a colocar de forma nova a questão do real?.

Se a visão torna-se prioritária, seus suportes e mecanismos de reprodução e criação expandem-se. A máquina coloca outras possibilidades, inclusive de acoplar ao humano suas peças e elementos mecânicos e eletrônicos. No percurso histórico desta relação temos as ficções literárias e fílmicas clássicas como Frankstein ou o Prometeu Moderno de Mary Shelley (publicado em 01/ 01/1818), o robô Maria, no filme Metrópolis de Fritz Lang (1929) ou recentemente, Neo, personagem chave em Matrix (filme de 1999), onde a "Revolutions" (filme de 2003) estaria no mundo virtual dos bytes, tornando o humano a combinação binária de números.

\footnotetext{
${ }^{2}$ COUCHOT, Edmont. Da representação à simulação: evolução das técnicas e das artes da figuração. In. PARENTE, André (org.). Imagem-máquina. Editora 34, p.38

${ }^{3}$ FABRIS, Annateresa. Redefinindo o conceito de imagem. Revista Brasileira de História. Vol. 18, n.35,. 1998. p.45

${ }^{4}$ Idem. p.46

${ }^{5}$ Idem.p 47

${ }^{6}$ QUÉAU,Philippe. O tempo virtual, In. PARENTE, André (org.). Imagem-máquina. Editora 34, p. 93

7 Idem. P.99
} 
Os estudos sobre imagem agregam muitas áreas do conhecimento e há muito vem ganhando corpo, especialmente pela Sociologia, Antropologia Visual, Semiótica e História da Arte, lembrando que esta última, em franca expansão, alarga suas fronteiras, ou melhor, refaz suas perguntas ao seu objeto de estudo.

As visualidades, ou o conjunto de imagens em vários suportes, também abrangendo o virtual, retorna a sua origem e recai no figurativo, e é neste campo que circunscreverei minha fala.

O figurativo remonta à condição humana básica em expressar por figuras, cores e formas os sentimentos, as críticas, as emoções que poderíamos dizer, vem das inscrições préhistóricas nas cavernas, em seu caráter místico, mas, também de registro de rituais e convenções sociais esboçadas em um grupo humano em conformação.

Tais dimensões de expressão humana tomam proporções no que Guy Debord aponta como uma "sociedade do espetáculo", onde as imagens ocupam todo espaço e a idéia do "presente perpétuo" e interpretação efêmera, informal altera e despotencializa a história. Só para lembrar a obra foi publicada em 1967, inspiradora de maio de 68 e traduzida no Brasil em 1997. Inicialmente em italiano, depois, traduzido para o francês. Suas reflexões, porém, não devem ser desconsideradas no quadro social, econômico, político e cultural vivenciado nos últimos decênios.

Aqui indago: neste mar de imagens quais as significações e repertórios interpretativos utilizados na leitura de imagens?

A transposição em linguagem textual auxilia a decifração visual, intercalando as linguagens visual e verbal, pois, a descrição não deixa de ser a mediadora da explicação. Segundo Baxandall, "nós não explicamos um quadro, explicamos observações sobre um quadro"8. Outro historiador, Peter Burke ${ }^{9}$, aponta que imagens podem testemunhar o que não pode ser colocado em palavras.

Minha intenção não é valorizar uma linguagem em detrimento de outra, mas, como outros autores apontam, o intercruzamento de vetores e fronteiras de estruturas de pensamento, ou seja, o que as palavras muitas vezes não conseguem expressar e o que uma imagem pode resignificar para outros somente sem a necessidade de verbalizar.

Lembramos que este re-significar atrelase também ao repertório cultural, emocional e sígnico dos indivíduos participantes. Pensemos no exemplo de três cegos descrevendo uma parte do elefante: estes não teriam a dimensão plena do conceito elefante, e se por um lado, não possuem a visão, desenvolveram outros sentidos como o tato e o olfato e instrumentalizam ferramentas interpretativas através do como falar, escolhendo palavras e signos para expressar o que "vêem" com os dedos.

Ao fazer uma leitura literal ou metafórica, descrevemos paisagens visivas, mas, muitas vezes não concatenamos uma lógica formalizada. "É mais fácil identificar os elementos de uma pintura do que compreender a lógica de sua combinação"10.

Para Peter Burke ${ }^{11}$, as lógicas de combinação possíveis para a leitura de imagens, retomando, Ernst Gombrich, por exemplo, refere-se à reconstrução de um programa pictórico, um afunilamento significativo do projeto ligado à suspeita de Gombrich de que a

\footnotetext{
${ }^{8}$ BAXANDALL, Michael. Padrões de intenção. A explicação histórica dos quadros. São Paulo: Cia das Letras, 2006.p.31.

9 BURKE, Peter. Testemunha ocular. História e imagem. Bauru: Edusc, 2004, p.38

${ }^{10}$ Idem. p.50

${ }^{11}$ Op.cit.. P.46
} 
iconologia de Panofsky era simplesmente um outro nome para a tentativa de ler imagens como expressões do "espírito da época". Mais à frente, o autor complementa que para interpretar a mensagem, é necessário familiarizar-se com os códigos culturais; um pouco o que veremos no que Baxandall chamaria de "el ojo de la época"12

Dentre as imagens figurativas optei por pensar rapidamente as pinturas históricas ${ }^{13}$.

Para Burke em um título muito sugestivo, "Pintores como historiadores do século XIX", a grande era da pintura da história foi o século XIX, especialmente sua segunda metade.
Podemos refletir, entre outras possibilidades, as narrativas feitas pelos "pincéis da história" ou "a fabricação do Estado", quais os tipos de história que eram pintados, quais os temas predominantes, a nacionalização do passado segundo os ícones nacionais, a ação de patronos e um segundo público: compradores de reproduções de pinturas históricas, gravuras ou litografias, o que poderíamos ampliar e incluir os livros didáticos e como esses remetem aos modos de enxergar o passado, as seleções do repertório visual e as retóricas visuais utilizadas.

Neste aspecto, tomemos rapidamente o exemplo do quadro abaixo:

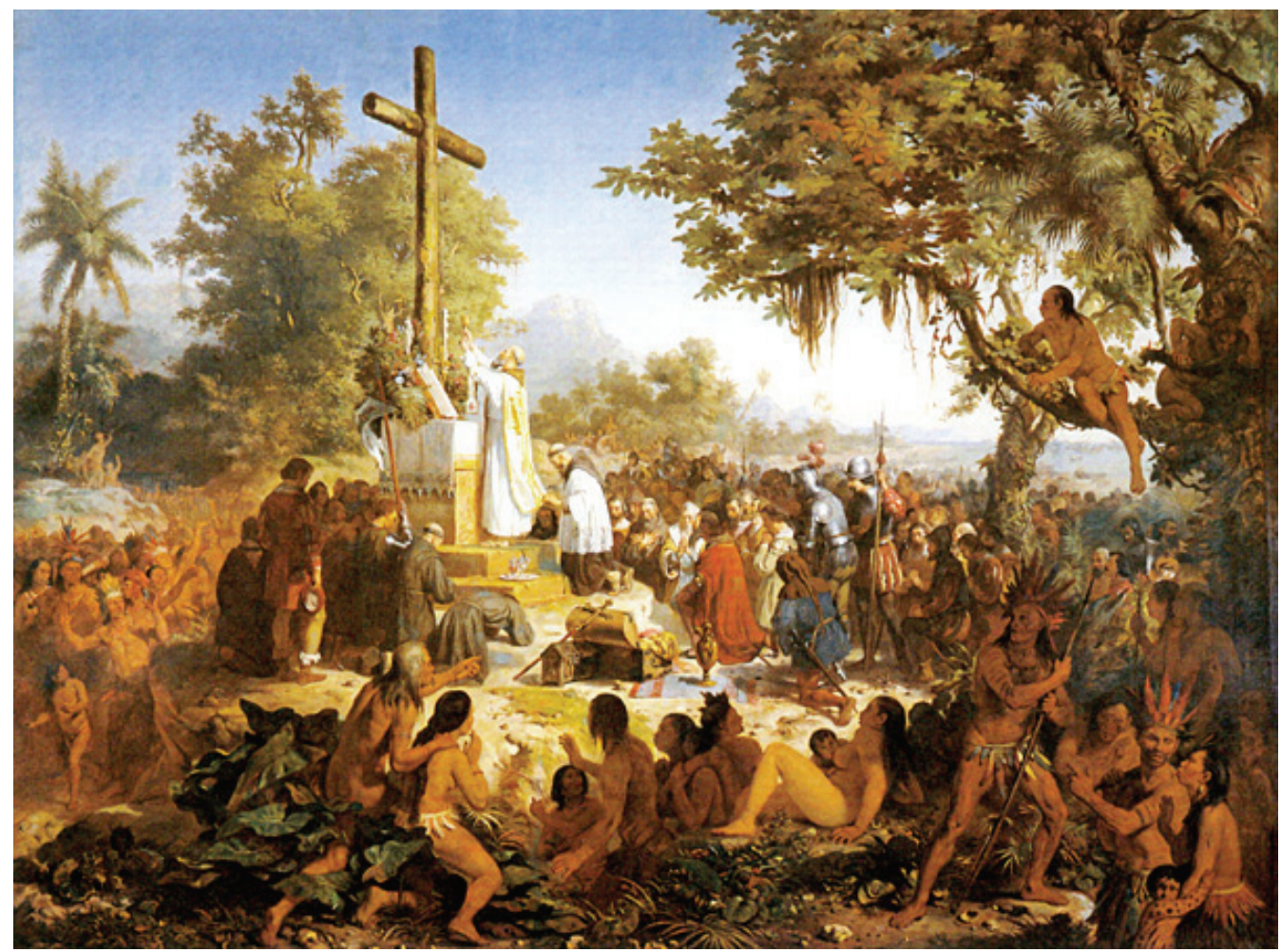

Quadro: A Primeira Missa no Brasil. Vítor Meirelles. 2,68 x 3,56m. 1861. Museu Nacional de Belas Artes, Rio de Janeiro.

\footnotetext{
${ }^{12}$ BAXANDALL, Michael. El ojo de la época. ( Pintura y vida cotidiana en el Renacimiento. Arte y experiencia en el Quattrocento. Barcelona, Gustavo Gili, 1988, traduzido no Brasil como Olhar renascente).

${ }^{13}$ As considerações sobre pintura histórica estão em Pintores como historiadores na Europa do século 19. In. MARTINS, José de Souza e outros (orgs.).O imaginário e o poético nas Ciências Sociais. Bauru: Edusc, 2005
} 
O quadro Primeira Missa no Brasil, de Vítor Meirelles foi executado em um contexto, onde a ação do Instituto Histórico e Geográfico Brasileiro, fundado em 1838, em conjunto com a Academia Imperial de Belas Artes, procurava demarcar os mitos fundadores de uma história nacional, fincada na proposta de narrativa delineada por Von Martius.

O conceito de nação operado é eminentemente restrito aos brancos, sem ter, portanto, aquela abrangência a que o conceito se propunha no espaço europeu. Construída no campo limitado da academia de letrados, a nação brasileira traz consigo forte marca excludente, carregada de imagens depreciativas do "outro", cujo poder de reprodução e ação extrapola o momento histórico preciso de sua construção. ${ }^{14}$

Para este "outro", baseado nas experiências jesuíticas, objetiva-se trazê-los para o interior durante a implementação de um "processo civilizador". Este discurso coaduna-se com os aspectos políticoestratégicos daquele momento, segundo Guimarães, onde a jovem monarquia, que constrói sua identidade a partir da oposição às formas republicanas de governo latinoamericanas, ao assegurar o controle sobre as populações indígenas fronteiriças garantirá o poder do Estado-Nação sobre este espaço.

À Academia Imperial de Belas Artes com um sistema de ensino pautado em referências do modelo da Academia de Belas Artes da França modela referências visuais, especialmente para a pintura histórica, utilizando-se de pesquisas em documentos históricos, mas, com uma composição plástica fundada em personagens com caráter heróico tendo ao fundo uma natureza exuberante a ser conquistada.

Jorge Coli ao comentar a "invenção da Primeira Missa", por Victor Meirelles, anota as recomendações de Araújo Porto-alegre para a composição deste quadro:

Araújo Porto-Alegre, diretor da Escola de Belas Artes do Rio, catalisador do romantismo indianista, exercendo atividades literárias, ao mesmo tempo que plásticas, foi animador de uma cultura artística de cunho nacional, insistira para que Meirelles se embebesse do relato de Caminha: "Leia cinco vezes o Caminha, que fará uma cousa digna de si e do país". Insistia também para que reproduzisse uma natureza tropical. ${ }^{15}$

Siman em um estudo sobre o imaginário de adolescentes mineiros acerca do descobrimento utilizando, em especial, o quadro Primeira Missa aponta que todos os alunos entrevistados identificaram a pintura "(...) dizendo ou o nome do quadro ou do que esse trata" frisando o quanto seja "(...) revelador de sua presença no repertório de representações dos estudantes"16

A autora avança nas considerações:

(...) Não é de se estranhar essa facilidade na identificação, e isso poderá se explicar não apenas pela experiência mais recente e pessoal desses sujeitos pesquisados, mas pela sua presença no imaginário coletivo da nação. Ressalta-se que 21 alunos, ou seja, $25 \%$ do total, não se limitaram a atribuir ao quadro o seu próprio título e, em suas respostas, já podemos destacar alguns elementos de interpretação que remetem

${ }^{14}$ GUIMARÃES, Manoel Luis Salgado. Nação e civilização nos trópicos: o Instituto Histórico e Geográfico Brasileiro e o projeto de uma história nacional. Estudos Históricos. Rio de Janeiro, n.01, 1988.p.7

${ }^{15} \mathrm{COLI}$, Jorge.A pintura e o olhar sobre si: Victor Meirelles e a invenção de uma história visual no século XIX brasileiro. In. FREITAS, Marcos César (org.).Historiografia brasileira em perspectiva. São Paulo: Contexto, 1998, p. 380

${ }^{16}$ SIMAN, Lana Mara de Castro. Pintando o descobrimento: o ensino de história e o imaginário de adolescentes. IN. FONSECA, Thais $\mathrm{N}$ de Lima e SIMAN, Lana M Castro. Inaugurando a história e construindo a nação: discursos e imagens no ensino de história. Belo Horizonte: Autêntica, 2001. 
quer a visões historiográfica mais recentes a invenção da descoberta - , quer a interpretações que associam a imagem ao surgimento da igreja no Brasil - leituras marcadas, certamente, por suas experiência culturais religiosas $(. . .)^{17}$

Essas ponderações são importantes na medida em que constatam as interpretações visuais dos adolescentes, mesmo temporalmente afastados, dialogarem com as premissas da tradição de narrativa plástica da Academia Imperial de Belas Artes, agregado ao fato que, mesmo com visões historiográficas recentes incorporadas à leitura visual, não conseguem derrubar as primeiras impressões.

Coli nos auxilia a refletir a força destas impressões ao comentar: "(...) sob a égide católica, associam-se, numa cena de elevação espiritual, as duas culturas. Criava-se ali o ato de batismo da nação brasileira. Momento prenhe de significados, que o projeto de construção de um passado histórico para o Brasil, ocorrido no século XIX, saberia explorar". ${ }^{18}$

Desta forma, o impacto da imagem na imaginação histórica, segundo Francis Haskell citado em Burke ${ }^{19}$, nos remete a como pinturas, estátuas, publicações e assim por diante permitem a nós, posteridade, compartilhar as experiências não verbais ou o conhecimento de culturas passadas e a maneira como estas experiências foram apropriadas, alimentando leituras ainda fortemente marcadas pelas suas premissas de origem, como citado no exemplo acima.

Mesmo em um nível de saturação de nosso mundo de experiências por uma quantidade crescente de imagens, pensemos os espaços de resistências. Entre pintores paisagistas da virada do século XIX ao XX, Claude Monet (1840-1926) e muitos impressionistas, por exemplo, rejeitavam o significado da paisagem e concentravam-se nas sensações visuais. Neste sentido, poderíamos começar a considerar as histórias das respostas às imagens e as tentativas de controle feitas em vários círculos de legitimação.

O sujeito propriamente dito ou programa iconográfico aceito pelo artista e o motivo por ele escolhido ou abordado por razões artísticas, ou seja, a questão da gênese da obra interfere, assim, com a de seu modo de significação. ${ }^{20}$

Partindo desta indagação reflitamos com Klein: O que esse processo representa? Como é que eu posso saber o que isso representa?, como captar entre as significações igualmente possíveis de uma obra, aquela que é a "melhor" e como saber que ela é "melhor" que outras?

Não se trata de qualificar significados, mas, como se dispõem as diferentes camadas de significação ou categorias de assuntos, depois, os meios objetivos de interpretação de que se dispõe, enfim, o "limite em que o trabalho de decifração encontra o famoso círculo de hermenêutica: é preciso haver compreendido para compreender"21.

Nesta mesma direção, Salgueiro nos auxilia a retomar as relações entre observador/imagem/discursos/decodificação.

Estamos então diante de um objeto "deslocado" do seu mundo/tempo e sobre o qual se acumulam discursos de diferentes

\footnotetext{
17 SIMAN. Op.cit. p.157-158.

${ }^{18}$ COLI. Op.cit. p. 380.

${ }^{19}$ BURKE, Peter. Op.cit. p. 16

${ }^{20}$ Klein, Robert. Considerações sobre os fundamentos da iconografia.In. A forma inteligível. SP; Edusp, 1998, p. 343

${ }^{21}$ KLEIN. Op.cit.. P. 344
} 
contextos/tempos, cada observador construindo a descrição segundo as formas de contemplação, bagagem cultural ou as formas de apropriação da sociedade em que se insere. Em conseqüência, resulta o abismo que Baxandall reconhece como difícil de transpor entre as imagens e as palavras desafio constante, relembrado durante todo o desenvolvimento da sua reflexão. ${ }^{22}$

A referência cultural particular a cada objeto analisado, a busca das suas condições de compreensão e percepção, as descontinuidades temporais das formas, a historicidade múltipla das obras, o tempo social da produção, circulação e recepção, as políticas culturais de reconfiguração ao integrarem coleções, museus, ou mercado da arte constituem elementos possíveis de intercruzamento de análises mais pertinentes ao objeto visual.

Também, o que Burke chama de habitus visuais ou cognitivos em que se inscreve a obra desloca a atenção de sua análise para sua leitura, pois, o leque de possibilidades e diferenças entre os artistas e a montagem das diferenças na composição visual re-modela a dinâmica da memória e oferece outras possibilidades mais abertas à análise do figurativo.

Neste leque de novos olhares sobre o figurativo, como nos remetemos a um dado conceito a partir da imagem canônica e viceversa? Ou como as pinturas de determinados fatos históricos cristalizam determinado conceito?

Neste universo imagético em constante transformação, como estabelecer elementos de leituras das imagens apresentadas?

As leituras das imagens, ou melhor, as possibilidades de tradução em palavras do que se vê, também é uma tarefa conflitante.
Passa pela percepção, o que ainda não é representação. Para Julio Plaza

Perceber uma coisa, contudo, não é ainda representa-la numa forma tangível. Nessa medida, a representação pressupõe mais do que a formação de um conceito perceptivo. Ela requer o que Arnheim chama de "conceito representativo", ou seja, a tradução de "conceitos perceptivos" em padrões que podem ser obtidos de um estoque de formas disponíveis num médium particular, de modo que os "conceitos representativos" se tornam dependentes do meio através do qual eles exploram a realidade. ${ }^{23}$

A importância do meio está na influência das qualidades materiais do signo, o provocar sensorial e a materialidade. Consideremos como exemplo as diferenças entre uma fotografia, um desenho e uma gravura que representam um mesmo objeto.

O viés proposto por Burke sinaliza outra condição possível de leitura. "Imagens são irremedialvemente mudas". Este autor complementa com um dizer de Michel Foucault "o que vemos nunca está no que dizemos" e agrega ainda a declaração de Roland Barthes (1915-1980) " Eu leio textos, imagens, cidades, rostos, gestos, cenas".

Se por um lado estas referências são operatórias, por outro a natureza estética da imagem parece resistir a esse tipo de análise, tornando-se, em certos casos e para certas imagens ou seus usos, limitativos. Na outra ponta, temos a idéia de que a imagem fala por si, portanto, sua compreensão é algo espontâneo, e desta forma, não necessitaria de códigos de inteligibilidade mais aprofundados.

A linguagem visual não é universal. Seus significados obedecem a um sistema de representações que se orientam por convenções que implica o exercício

\footnotetext{
${ }^{22}$ SALGUEIRO, Heliana Angotti . Prefácio. In. BAXANDALL, Michael.. Padrões de intenção. SP: Cia das Letras, 2006

${ }^{23}$ PLAZA, Julio. Tradução intersemiótica. SP: Perspectiva, 1987. p.48
} 
estruturado de (de)codificação. Entre a imagem e o que se representa, existe uma série de mediações, que não restituem o real, mas, reconstrói, voluntária ou involuntariamente a apreensão do real. Como diz Miriam Moreira Leite, "(...) a imagem não explica a realidade. Convida a recriá-la e a revivê-la"24

A autora cita Bartlett (1932) onde " (...) as imagens fluem entre si, condensam-se e combinam-se em cada experiência mental do indivíduo, podendo parecer do exterior inadequadas ou mesmo incoerentes" 25 . O observador da imagem incorpora-a entre suas imagens mentais, transferindo-a de um tipo para outro de memória. No caso estudado pela pesquisadora é a fotografia, mas, podemos estender a outros tipos imagéticos.

"Ao que é impossivel descrever, torna-se indiscutível a prioridade da imagem visual, por sua capacidade de reproduzir e sugerir, por meios expressivos e artísticos, sentimentos, crenças e valores"26.

Pelo fato de nem sempre a imagem ser imediata, o exercício da escrita e da proposição oral complementam-se, não restringindo a percepção visual somente à organização intuitiva.

A polissemia da mensagem visual envolve ramificações de associações, uma multiplicidade de símbolos e interpretações e possui como variável, um repertório cultural construído em meio às relações sociais e históricas, implicando também pela ótica do leitor, a seleção de significados, escolhendo alguns, excluindo outros.

A imagem abaixo ilustra, em seu primeiro e melhor sentido, as considerações acerca da polissemia da mensagem visual.

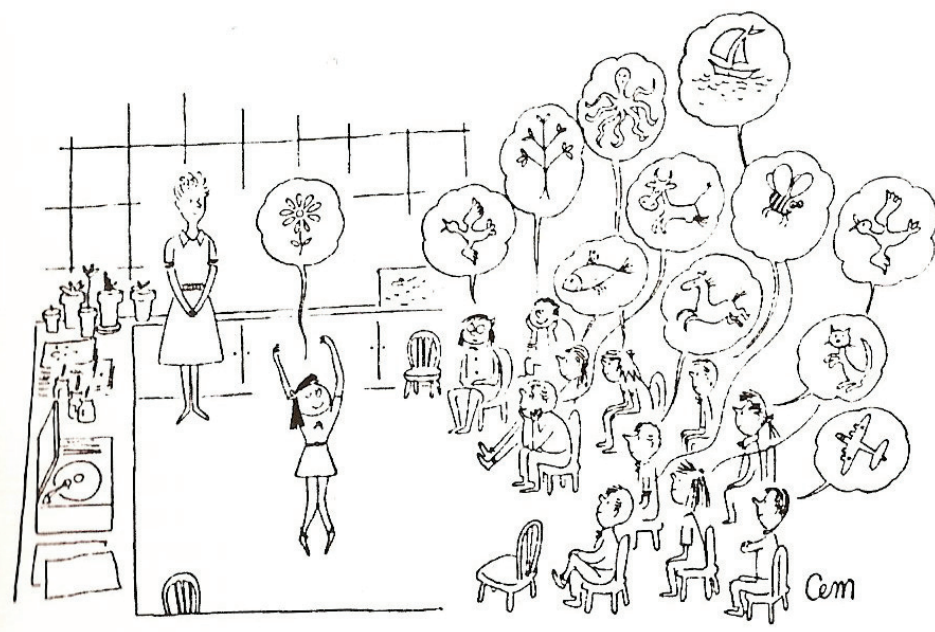

Desenho de Cem, publicado em The New Yorker @ 1961

Retirado de SAMAIN, Etienne.Questões heurísticas em torno do uso das imagens nas Ciências Sociais. In.BIANCO, B. Feldman e LEITE, Miriam L M. Desafios da imagem. Campinas: Papirus, 1998. P.58

\footnotetext{
${ }^{24}$ LEITE, Miriam M. Texto visual e texto verbal. In. BIANCO, Bela e LEITE, Miriam M. (orgs.). Desafios da imagem. Campinas; Papirus, 1998. p.41

${ }^{25}$ Idem. p.43

${ }^{26}$ Ibidem. p. 44
} 
Uma imagem é carregada de significado mesmo que não se saiba formulá-la adequadamente em termos discursivos ou conceituais.

\begin{abstract}
(...) em torno de cada imagem escondem-se outras, forma-se um campo de analogias, simetrias e contraposições. Na organização desse material, que não é apenas visivo, mas, igualmente conceitual, chega o momento em que intervém minha intenção de ordenar e dar um sentido ao desenrolar da história - ou antes, o que faço é procurar estabelecer os significados que podem ser compatíveis ou não com o desígnio geral que gostaria de dar à história. ${ }^{27}$
\end{abstract}

Desta forma, o desígnio de minha narrativa, descrição ou interpretação, desenha as possibilidades de leituras, apreensões e sentidos.

Apesar de refletir sobre a Exatidão, em seu texto nas propostas para o próximo (este) milênio, Ítalo Calvino, nos conduz ao poder das palavras imprecisas, vagas e indeterminadas, explorando as imagens construídas a partir do indefinido, do sabor e da poesia dos termos. Desta forma, as palavras não possuem a capacidade definitiva e exata de precisão e constroem pontes entre a imagem visiva e a expressão verbal. Por outro lado, a exploração do potencial semântico das palavras e suas conotações, comportam o que o autor alega sobre a multiplicidade e a visibilidade, condições essenciais naquele século e neste milênio.

Partindo desta idéia indago: a"leitura" de imagens tornou-se "lugar comum"? Se assim o é, porque ainda a dificuldade de historiadores e professores de história em recolocá-la enquanto um documento que não seja ilustrativo e tomá-la como um viés potencialmente rico de possibilidades como também de limites?
Este panorama inicial, talvez abrangente, é para situarmos duas pontas de um mesmo processo: como são utilizadas as imagens no ensino de história pelos professores e como os alunos lêem tais imagens?

Iniciemos pelos professores de história: quais são as dúvidas e os desafios colocados na construção do conhecimento histórico a partir da imagem?

Os professores de história reconhecem as potencialidades da imagem enquanto ferramenta de comunicação pedagógica e com maior ou menor insistência recorrem às imagens, e as mais diversas, em uma situação geralmente de transmissão (notem que escrevi transmissão e não mediação) aos alunos de determinados conteúdos programáticos, para motivá-los em um momento de aprendizagem, captar a atenção ou estabelecer conexões com temas apresentados.

Observamos, porém, um predomínio da palavra oral e da palavra escrita e uma insistência na comunicação, muitas vezes, pouco diversificada, restringindo o suporte visual meramente à ilustração de um conhecimento dado como devidamente elaborado.

Pensar a imagem, em contexto educativo ou fora dele, tem sido, para nós, oscilar numa atitude de adesão/rejeição face aos modelos e instrumentos de tipo algorítmico, atomista, como são os da teoria da informação, da lingüística, da cibernética, da axiomática, em geral do estruturalismo. ${ }^{28}$

Variáveis interferem com o tipo e a quantidade de informação que vai ser extraída da mensagem. A exposição dos alunos a determinados elementos simbólicos (nomeadamente os que fazem parte da

${ }^{27}$ CALVINO, Ítalo. Seis propostas para o próximo milênio. São Paulo: Cia das Letras, 1990. p.104-105

${ }^{28}$ CALADO, Isabel.A utilização educativa das imagens. Porto: Porto Editora, 1994.p. 20 
linguagem visual) tem conseqüências profundas no seu desenvolvimento e domínio de ferramentas interpretativas. Há caminhos incontroláveis da imagem, que levam da informação à evocação, à magia, ao devaneio, ao desinteresse, à saturação, à emoção.

Calado ao pesquisar a utilização educativa das imagens por professores aponta algumas questões, que acredito, possamos transpor em nossas salas de aula de história.

Como os professores exploram as competências específicas da imagem? Qual a forma de tratamento dessa informação? Normalmente as funções associadas à utilização das imagens são: motivar, interessar, tornar compreensível o complexo/ abstrato, documentar, memorizar, mostrar novos aspectos, evocar, interligar, explorar aspectos ocultos, transmitir pontos de vista, emoções, tornar a aula mais atraente e convencer os alunos de um ponto de vista.

A maneira de dispor os contextos ensino e aprendizagem a partir da imagem é normalmente aquele voltado à apresentação de novos assuntos, para a interrogação de idéias, na perspectiva de realizar uma síntese já apresentada, aplicações práticas com exercícios, avaliação e revisão de matéria. ${ }^{29}$

Desta forma, as imagens usadas em sala de aula não devem sê-lo gratuitamente, mas, é necessário conhecer seus componentes semânticos para adequá-los aos objetivos propostos. Assim, o desafio e o limite imposto ao professor de história serão de redimensionar e explorar as competências específicas da imagem, não somente para motivar e envolver, mas re-elaborar, recodificar, ordenar e organizar conceitos, transformando uma relação sócio-afetiva com a imagem em uma situação de cognição.
Vejamos agora, na outra ponta, a ótica dos alunos quanto ao uso de imagens nas aulas de história.

Em uma pesquisa com alunos do ensino fundamental ( $8^{a}$ série) e médio em 2006 com análises parciais, em uma amostragem de 30 questionários, verificamos as considerações do alunado para a pergunta: Nas aulas de história, quando você olha uma imagem, o que você procura observar?

As respostas apontaram principalmente para aspectos gerais como: "a cor, gestos, objetos e roupas", "o que os personagens estão fazendo", " as tintas e traços, detalhes, coisas diferentes", "coisas que não vemos em qualquer imagem", "o que me ajudaria a aprender, lugares"; e as referências para semelhanças e índices de reconhecimento: "observar o físico da imagem para ver o que representa", "semelhanças com os dias de hoje, saber como era a história antes".

As indagações quanto à pintura, cores e formas pontuo na bem-vinda influência dos colegas professores de artes, mas, além de aprender com eles e seu equipamento de análise, poderíamos ultrapassar nossos conceitos prévios, apropriando-nos de seus estudos e adequando-os ao nosso referencial, para não limitar a arte à pintura e provavelmente a uma única época. As referências no tocante a indícios de reconhecimento pressupõem, mesmo que vagamente, exercícios de leitura, em uma tentativa de identificar permanências e rupturas no interior do processo histórico.

A questão dois propunha "para que serve a imagem na aula de história" e as respostas mais comuns podem ser agrupadas como "entender melhor o conteúdo": "observar as pessoas daquela época", "entender melhoro

${ }^{29}$ CALADO. Op.cit.p. 22 . 
assunto, retratando alguns conhecimentos, aprender a história do mundo", "confirmar um fato, mostrar e ensinar de um jeito em que seja menos teórica", "acho que é para ajudar na cooemprenção (sic) da matéria", "para nos mostrar integralmente o assunto discutido", " pra ver se nós aprendemos de um jeito mais legal"

Estas respostas dialogam com os termos que podemos chamar de "motivação": "para sabermos mais sobre a história e além de "prender" o aluno, ou seja, se fazer com que ele se interessar mais pela aula", " para entendermos melhor o cotidiano do que está sendo estudado na aula", " para aprendermos mais e para conhecer as coisas nos mínimos detalhes", "serve então como uma ferramenta de ensino", " imaginar como viviam, assunto seja mais explicável", "a gente vai entendendo vendo como era as coisas antigamente", "para nós ter uma "nossão" (sic) mais realista do assunto" "para não apenas ouvirmos o assunto".

O conceito de história associado a um conhecimento global e totalizante ainda permeia as respostas dos alunos, onde o "mostrar integralmente o assunto", "conhecer o cotidiano", "as coisas nos mínimos detalhes" e "ter uma noção mais realista do assunto" são indicativos das apreensões de nosso alunado quanto ao conceito de história em si e o conhecimento produzido pela historiografia mais voltada ao cotidiano e em perspectiva micro ou mais detalhada, contraditoriamente, em oposição ao integral proposto na resposta dos alunos. Estas contradições expõem muito mais as batalhas de discursos no interior $\mathrm{da}$ historiografia redimensionadas, em outra clave, ao conhecimento histórico escolar.

A questão três solicitava enumerar as diferenças entre a imagem de uma fotografia, de uma pintura e a do cinema. Vejamos as respostas: "Cinema é uma forma de voltar no tempo, aprender se divertindo; fotografia: entender o que houve, pintura: resgatar o passado de forma rápida", "Cinema as pessoas se mexem, fotografia retrata uma parte da vida das pessoas, pintura retrata coisas da época", "Cinema é quase perfeito", " Cinema é mais real", "Fotografia nos mostra a realidade, pintura nos mostra o que o pintor expressa e cinema é ficção", "Pintura é mais fácil visualizar", "Cinema é mais importante porque dá continuidade" (palavra muito utilizada nas respostas), "Pintura você vê a arte, cinema você vê a história", "Cinema é o mais fácil de todos", "Pintura é mais emocionante" .

Aqui observamos o trânsito, ou certa confusão, sobre as especificidades de cada linguagem e o sentido emocional despertado pelas mesmas, sintetizado na frase "Fotografia $=$ real, pintura = ilustração, cinema $=$ veritico $($ sic)", onde, além dos referenciais de realidade e verdade estarem transpostos nos adjetivos utilizados, há o predomínio de que o cinema é mais fácil de compreender a história, desvinculado do fato de ser também uma construção social e histórica como a pintura e a fotografia também o são.

Para a questão número quatro foi proposta a relação do professor de história ao explorar em sala de aula algum tipo de imagem. As respostas indicaram, em sua maioria, que a aula fica mais prazerosa e a apreensão do assunto seria melhor. Os comentários adicionais foram: "Entendo melhor, pois a imagem não muda a aula, mas, sim ajuda a entender melhor o assunto" "Muda um pouco o jeito teórico da aula", "Ajuda a aprender, só que eu tenho dificuldade" "É mais fácil entender porque quando tem uma imagem sobre certo assunto, você imagina", "Não me ajuda porque eu me distraio assistindo filme 
ou outra coisa", "Para mim passar filme, figuras em sala não ajuda nada só que a aula fica mais legal", "Porque você imagina com a ajuda da figura o que aconteceu".

As relações entre imagem/ imaginação permitem algumas considerações. Não somente quanto a visualizar determinada situação, mas, como estas estabelecem, na medida em que são apontadas pelo professor, as relações do lugar social, o recorte político, os motivos, a composição, ou seja, como desvendar o enigma das imagens pela mediação da palavra. Outro aspecto a considerar seria que mesmo sendo mais fácil entender, nem por isso, garante a eficácia da aprendizagem, pois, o contexto e a maneira de expor a imagem em sala de aula ficaria restrito à novidade, ficando "mais legal".

Pelas falas dos alunos, verificamos que apesar da vivência do virtual, o real está no cinema ou na foto que mostra a realidade, o que podemos inferir, acerca da necessidade de elementos palpáveis para os jovens em definir o difícil conceito de realidade, no seu aspecto mais próximo ao significativo, como nos trechos: "mais verdadeiro", "para sentir". O como e em qual intensidade as apropriações são realizadas fica a especulação.

Até que ponto as respostas dos alunos não indicam o uso das imagens em sala de aula como elemento ilustrativo ou corroborativo da fala do professor de história? As respostas que tocam sobre a disciplina ser menos teórica e "o assunto mais explicável" nos remete à organização do conhecimento histórico na medida que envolve saberes em seus mais variados níveis de abstrações em um grau de variáveis de habilidades cognitivas, que constrói conceitos e elementos de leitura em uma complexa arquitetura e hierarquia de estruturas de pensamento.Desta forma, a imagem é tanto uma estrutura quanto uma ponte para refletirmos acerca da organização de um dado conhecimento, especialmente, na sala de aula.

\section{Considerações finais}

Proponho uma provocação em dois sentidos: Primeiro instigar os professores quanto ao uso organizativo conceitual, de códigos, contextos e tecnologias sobre e com a imagem. Mesmo com a sua saturação pela virtualidade, vemos, mas, não enxergamos, naturalizamos nosso olhar, dessensibilizamos nossa percepção.

Por outro lado investigar como os alunos percebem as imagens e as relacionam a uma construção de conhecimento histórico que não seja rotulado de mais real, menos ficção, mais movimento, mas, promotor de referenciais capazes de promover outras leituras visuais em seus mais variados suportes. Não no sentido de leituras "corretas" ou "incorretas" a partir de determinados códigos ou controle, mas, no indicativo de Burke, enquanto uma testemunha ocular, como uma história das respostas às imagens, percebendo, como ocorre na pesquisa em outros tipos de documentos, as fragilidades das interpretações.

Não desconsidero as transformações tecnológicas e a decomposição em inúmeras possibilidades das imagens, mas, priorizo o predomínio do figurativo e a relação com as imagens fixadas em livros didáticos ou seus excessos e filmes como recursos e pensar o quanto nós, professores, não somos responsáveis por esta visão simplista e naturalizada dos acontecimentos, dos fatos, dos personagens em nossa narrativa histórica.

Alegamos equipamentos avariados, necessidade de adaptações físicas na sala de aula, a dificuldade na manipulação de equipamento, desinteresse dos alunos, despesas e o cumprir o planejamento, mas, temos alguns aliados, como, menor número de re-explicações, os episódios imprevistos e enriquecedores, o diálogo mais fácil com os 
alunos e talvez uma maior fluência promovida pela possibilidade de imaginar.

Ao mesmo tempo, ao falarmos sobre as inúmeras possibilidades da virtualidade promovida pela internet temos que considerar a exclusão digital que afeta a muitos e as contradições das realidades escolares não somente no país, mas, em uma mesma cidade e seu entorno urbano e rural, o que nos recoloca, em outro prisma, a possibilidade do uso da imagem em outro registro, como as propagandas, out doors, livros didáticos, revistas, jornais entre outros.

Devemos considerar também as tensões, ambigüidades e contradições entre a imagem visual, o texto escrito e o contexto social de uma época, bem como, as formas de expressão visual, as metáforas e analogia, à retórica das imagens, ao dinamismo simbólico e a sua conexão com outros símbolos que dizem respeito à conceituação verbal e às categorias de entendimento.

Samain nos alerta:

Inútil tecer outras considerações sobre um tema conhecido: o da revolução perceptiva introduzida pela informática e por seus satélites, lugar de um saber e de um poder que se exercem diretamente sobre o corpo do observador. Pode-se gostar dela, podese recusa-la, resistir-lhe simplesmente ou, ao contrário, desejar que seja muito mais do que essa criança que ainda engatinha. Eis pontos de vista. ${ }^{30}$

Neste ponto de vista, devemos lembrar continuamente que a informática se insere em uma malha de relações sociais, tecnológicas, econômicas e institucionais não inocentes e no qual nos enredamos intrinsecamente. Aliada ou demonizada, inserida ou excluída em todas as possíveis probabilidades combinatórias, a informática é ferramenta social e educacional a ser mais explorada.

Uma outra provocação aos professores: a proposição dentro da complexidade do conhecimento histórico em organizar conceitos a partir da imagem. Tomar a imagem em sua complexidade e leitura e estabelecer condições de conexões que não sejam somente para que o ensino de história seja mais "explicável", conforme a observação do aluno. Ou seja, pensar a imagem enquanto potencialidade na organização de elementos e habilidades pertinentes ao ensino de história: discriminar, analisar, sintetizar, comparar, verificar permanências e mudanças, situar no tempo e no espaço a passagem e a ação de homens e mulheres.

Se ainda hoje existem dubiedades e ambigüidades quanto a isto, abrir campo para outras investigações: como o aluno compreende e organiza conceitos a partir de imagens em pinturas, fotografias, caricaturas, cinema. As respostas apontam, mesmo com décadas de uso em sala de aula, das chamadas "linguagens culturais", percepções ainda falhas quanto ao que é apresentado enquanto realidades e "verdades" ainda cristalizadas.

O exercício da crítica restrito a estas posições correta ou incorreta, verdadeiro ou falso, estreitam as outras possibilidades de apresentação, pois, a multiplicidade dos personagens e agentes de um momento histórico também o é e muitas vezes, ao selecionar, recortar e matizar um tema, esquecemos que existe a árvore e a floresta, mas, cada árvore é única e a floresta , assim como a árvore, pode ser vista sob várias óticas.

\footnotetext{
${ }^{30}$ SAMAIN, Etienne. Questões heurísticas em torno do uso das imagens nas Ciências Sociais. In. BIANCO, Bela F e LEITE, Miriam Moreira (orgs.). Desafios da imagem. Campinas: Papirus, 1998, p. 59.
} 
O deleite visual também desenvolve a percepção, mesmo quando valoramos como belo e feio,sendo no entanto, melhor apreciado na medida em que filtre os excessos não estacionando somente na leitura, mas, entender, estender e olhar de novo, onde os retratos nas paredes também nos espiam.

Muitos pensam e não verbalizam, em uma sociedade de resultados imediatos, falar de fruição, estético, valores e olhar talvez sejam desnecessários. Ao permitirmos que se naturalize ver crianças portando armas ao invés de lápis, tinta e livros, é aceitar o inevitável da barbárie e renegar uma proposição esquecida das ciências humanas e o ensino: a formação humanística do indivíduo que necessita ser recuperada.

\section{Referências Bibliográficas}

BAXANDALL, Michael. El ojo de la época. (Pintura y vida cotidiana en el Renacimiento. Arte y experiencia en el Quattrocento) Barcelona: Gustavo Gili, 1988.

BAXANDALL, Michael. Padrões de intenção. A explicação histórica dos quadros. São Paulo: Cia das Letras, 2006.

BURKE, Peter. Testemunha ocular. História e imagem. Bauru: Edusc, 2004.

CALADO, Isabel. A utilização educativa das imagens. Porto: Porto Editora, 1994.

CALVINO, Ítalo. Seis propostas para o próximo milênio. São Paulo: Cia das Letras, 1990.

COLI, Jorge. A pintura e o olhar sobre si: Victor Meirelles e a invenção de uma história visual no século XIX brasileiro. In. FREITAS, Marcos Cézar (org.). Historiografia brasileira em perspectiva. São Paulo: Contexto,1998.

COUCHOT, Edmont. Da representação à simulação: evolução das técnicas e das artes da figuração. In. PARENTE, André (org.). Imagemmáquina. Editora 34

FABRIS, Annateresa. Redefinindo o conceito de imagem. Revista Brasileira de História. Vol. 18, n.35.

GUIMARÃES, Manoel Luis Salgado. Nação e civilização nos trópicos: o Instituto Histórico e Geográfico Brasileiro e o projeto de uma história nacional. Estudos Históricos. Rio de Janeiro, n.01, 1988.

KLEIN, Robert. Considerações sobre os fundamentos da iconografia.In. A forma inteligível. São Paulo: Edusp, 1998.

LEITE, Miriam M. Texto visual e texto verbal. In. BIANCO, Bela e LEITE, Miriam M. (orgs.). Desafios da imagem. Campinas: Papirus, 1998.

MARTINS, José de Souza e outros (orgs.).O imaginário e o poético nas Ciências Sociais. Bauru: Edusc, 2005.

QUÉAU,Philippe. O tempo virtual. In. PARENTE, André (org.). Imagem-máquina. Editora 34.

PLAZA, Julio. Tradução intersemiótica. São Paulo: Perspectiva, 1987.

SALGUEIRO, Heliana Angotti . Prefácio. In. BAXANDALL, Michael. Padrões de intenção. São Paulo: Cia das Letras, 2006.

SAMAIN, Etienne. Questões heurísticas em torno do uso das imagens nas Ciências Sociais. In. BIANCO, Bela F e LEITE, Miriam Moreira (orgs.). Desafios da imagem. Campinas: Papirus, 1998.

SIMAN, Lana Mara de Castro. Pintando o descobrimento: o ensino de história e o imaginário de adolescentes. IN. FONSECA, Thais $\mathrm{N}$ de Lima e SIMAN, Lana M Castro. Inaugurando a história e construindo a nação: discursos e imagens no ensino de história. Belo Horizonte: Autêntica, 2001. 
